\title{
Consecutive epidemiological study of right ventricular dysfunction at a reference hospital
}

\author{
Francisco Buendía-Fuentes ${ }^{1 *}$, Luis Almenar-Bonet ${ }^{1}$, Rosario Vicente-Guillén², Juan Bonastre-Mora ${ }^{3}$, Raquel López ${ }^{4}$, Ana Osa-Sáez ${ }^{5}$, \\ Luis Martínez-Dolz' ${ }^{1}$ Ignacio Sánchez-Lázaro ${ }^{1}$, Vicente Miró-Palau ${ }^{5}$ and Antonio Salvador-Sanz ${ }^{1}$ \\ *Correspondence: franbuendia@gmail.com \\ ${ }^{1}$ Heart Failure and Heart transplant Unit, Cardiology department, Polytechnic University Hospital La Fe. Valencia, Spain. \\ ${ }^{2}$ Anesthesiology resuscitation department, Polytechnic University Hospital La Fe. Valencia, Spain. \\ ${ }^{3}$ Critical care medicine department, Polytechnic University Hospital La Fe. Valencia, Spain. \\ ${ }^{4}$ Pulmonology department, Polytechnic University Hospital La Fe. Valencia, Spain. \\ ${ }^{5}$ Cardiac Imaging Unit, Cardiology department, Polytechnic University Hospital La Fe. Valencia, Spain.
}

\begin{abstract}
Background and purpose: Right ventricular dysfunction (RVD) has been described as an independent factor for morbidity and/ or mortality in various nosological entities. However, there are no data on its true prevalence in hospital environments. The present study aims to discover the prevalence of this pathology at a specialized hospital center, as well as the characteristics of the patients affected.

Methods and results: An observational and prospective study analyzing 7636 echocardiographs performed consecutively over a 20 -month period. An etiological classification into four categories (cardiac cause, pulmonary thromboembolism, pneumopathy and idiopathic pulmonary hypertension) was proposed. 442 RVD cases were detected and classified, which is $5.78 \%$ of the examinations performed. Most of the cases (87.56\%) presented prior cardiopathy as the origin of RVD. Only $12.44 \%$ presented a non-cardiac cause for RVD. Differences were detected in the demographic and echocardiographic characteristics of patients, depending on the etiology of the RVD.

Conclusions: With a prevalence of $5.78 \%$ of all the echocardiographs performed in a specialized hospital, the significance of RVD is confirmed. The most frequent etiological factor for this disease is the existence of prior heart disease.
\end{abstract}

Keywords: Heart failure, right ventricular dysfunction, epidemiologic methods, congenital cardiopathy

\section{Introduction}

Historically, the right ventricle (RV) was considered a simple reservoir for pulmonary circulation [1-3] but it is now seen as a key element in the prognosis for various pathologies, both cardiac and extracardiac [4-5]. In recent years, the volume of scientific production focuses on the right ventricle has significantly increased [2,6-11].

Right ventricular dysfunction (RVD) has proved to be an independent factor for morbidity and/or mortality in patients with heart failure, acute ischemic cardiopathy, post-surgery heart and advanced valve disease [12-17]. In terms of congenital heart disease, RV dysfunction, whether systemic or sub-pulmonary, is a powerful marker for mortality and cardiac events [18-19]. In other non-cardiological entities, such as pulmonary arterial hypertension, pulmonary thromboembolism, adult respiratory distress syndrome or sepsis, RVD is also considered to be an important marker for morbidity and/or mortality [20-22].

RVD is a serious, common and little-studied pathology. Therefore, finding out the true prevalence of this disease and its most common etiological causes at a specialized hospital center is of utmost interest. Although there are studies of the prevalence of RVD focused on various etiologies [23-24], there are no broad single-center, epidemiological studies with a global approach to the problem. These data could be important in terms of allocating resources and creating units specializing in this pathology.

Magnetic resonance imaging of the heart is considered the best diagnostic method to define RVD [9]. However, it is not very practical or accessible. Hence, echocardiography seems to be the best method for an epidemiological approach in the "real world" [9]. In the present study, simple echocardiographic parameters have been selected to define RVD, bearing in mind the limitations of these parameters.

The main objective of this work was to analyze the prevalence of RVD at a reference hospital. Further objectives were to define the etiologies responsible for RVD and compare clinical and echocardiographic characteristics according to etiological group and the existence of pulmonary hypertension.

\section{Methods}

In order to conduct this project, a multidisciplinary study group, known by acronym DIFUNDE, comprising the fields of 
Buendia-Fuentes et al. Cardiovascular System 2014,

cardiology, pulmonology, resuscitation, intensive medicine, internal medicine and cardiovascular imaging was established and a joint database was produced to include all RVD patients.

\section{Type of study and population}

A prospective, observational, single-center study was planned with consecutive inclusion of all adult patients, both outpatients and inpatients, who had undergone a regulated echocardiographic study within a 20-month period (from November 2010 to July 2012). Urgent, non-regulated studies, transesophageal studies, ischemic-provoking studies, and studies that could not be analyzed due to a poor acoustic window (Figure 1) were excluded.

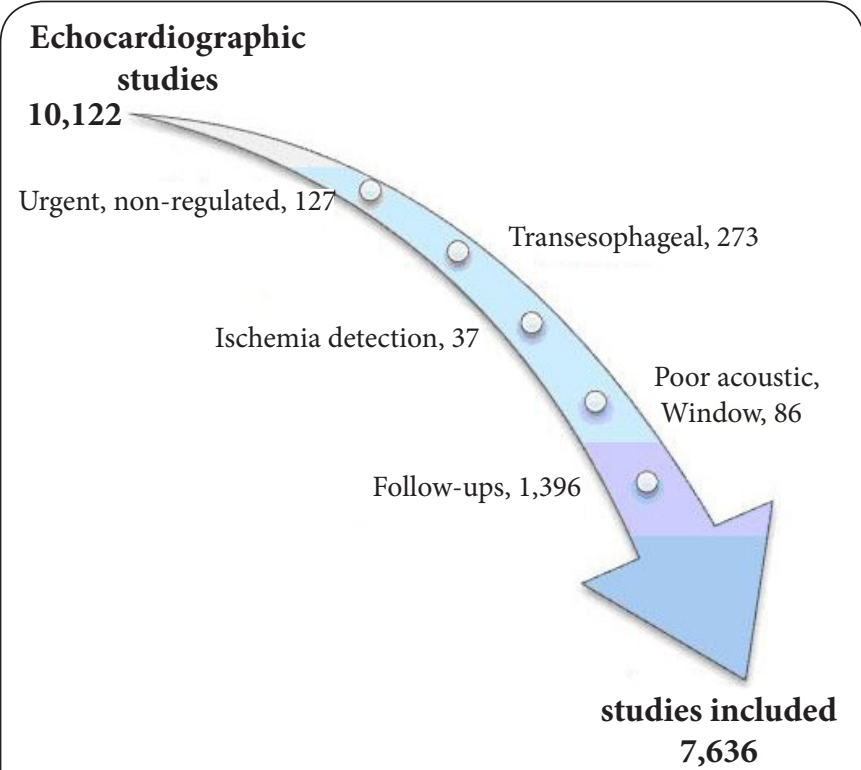

Figure 1. Echocardiographic studies performed during the inclusion period of the study. Only transthoracic studies conducted in a regulated manner in which right ventricular function could be correctly assessed were included.

Echocardiographic follow-ups performed on the same patient during the study period were also excluded. The figure shows the echocardiograms excluded due to each cause.

A total of 7636 echocardiographs with an adequate assessment of the right ventricle function were included.

The present study was carried out in a center comprising 1265 beds for adult hospitalization, which hosts more than 700,000 outpatient visits every year, contains a unit for adult congenital cardiopathies and heart transplant, and provides sustained health care for heart surgery, with an average of 500 interventions per year.

The study was approved by the Clinical Research Ethics Committee at the center ("Estudio del Fallo Cardíaco Derecho. Registro y Análisis Observacional", Right ventricular failure study. Records and observational analysis. No. 2010/0273).
Definition of right ventricular dysfunction and other echocardiographic data

The study of right ventricular function using echocardiography can be approached through various methods [9-10]. With the objective of globalizing the RV study, the most simple and easy-to-use echocardiographic parameters were included in the present work. Thus, two function parameters were included: tricuspid annular plane systolic excursion [25] (TAPSE) and maximum tricuspid annular $\mathrm{S}$ wave velocity using pulsed tissue Doppler [26]. The parameters included were quantified according to guidelines in literature [25-26]. For the statistical study, patients with right ventricular dysfunction were considered to be those who presented any of the following measurements: TAPSE $<15 \mathrm{~mm}$ and/ or S-wave $<10 \mathrm{~cm} / \mathrm{s}$ and/or baseline diameter $>42 \mathrm{~mm}$ on a 4-chamber view.

Apart from right ventricular baseline diameter and function, left ventricular dimensions and function, the existence of valvulopathy and the estimation of systolic pulmonary artery pressure (sPAP) were also gathered according to the gradient between the right atrium and ventricle in systole quantified by tricuspid regurgitation. Pulmonary arterial hypertension was considered as and PAP greater than $50 \mathrm{mmHg}$.

\section{Etiological groups of right ventricular dysfunction}

According to the criteria of different specialists (cardiologists, pulmonologists, intensive care specialists, anesthesiologists, rheumatologists, and internal medicine specialists), and for the purpose of etiologically classifying RVD patients, 4 etiological categories were created (cardiac cause, pulmonary thromboembolism, pneumopathy, idiopathic pulmonary arterial hypertension/immune cause), which comprised 9 groups. These are presented in (Table 1). Cardiac cause category is divided in four different groups: chronic and acute cardiopathy, congenital cardiopathy and post-surgical dysfunction. Chronic and acute cardiopathies include whatever sort of etiology (ischemic, valvular, myocarditis, idiopathic, hypertensive cardiomyopathy, hypertrophic cardiomyopathy, tachycardiomyopathy...) leading to right ventricular dysfunction. When the disease evolution was less than one month was considered as acute cardiopathy, other cases were classified as chronic. Cardiac cause category includes as a different group congenital cardiopathy. This group was classified into 4 pathophysiological models (Subpulmonary RV with volume overload, sub-pulmonary RV with pressure overload, systemic RV, systemic-pulmonary shunt with pulmonary artery hypertension).

RVD within the first month of cardiac surgery was classified in the post-surgical dysfunction group; making difference between heart transplant and the rest of surgical interventions.

Furthermore, the "cardiac cause" category included 4 general types of heart involvement based on their pathophysiological origin: systolic dysfunction (ejection fraction less than 35\%), diastolic dysfunction (restrictive or pseudonormal pattern), 
Buendia-Fuentes et al. Cardiovascular System 2014,

http://www.hoajonline.com/journals/pdf/2052-4358-2-1.pdf

doi: 10.7243/2052-4358-2-1

Table 1. Etiological groups of right ventricular dysfunction.

\begin{tabular}{|c|c|c|}
\hline \multirow{4}{*}{$\begin{array}{l}\text { Cardiac cause } \\
(\mathbf{n}=\mathbf{3 8 7})\end{array}$} & Chronic cardiopathy $(\mathrm{n}=250)$ & \multirow[t]{2}{*}{ Valvular, ischemic, hypertensive, idiopatic, hypertrophic, tachycardiomyopathy } \\
\hline & Acute cardiopathy $(\mathrm{n}=12)$ & \\
\hline & Congenital cardiopathy $(\mathrm{n}=74)$ & $\begin{array}{l}\text { Sub-pulmonary RV with volume overload } \\
\text { Sub-pulmonary RV with pressure overload } \\
\text { Systemic RV } \\
\text { Systemic-pulmonary shunt with pulmonary artery hypertension }\end{array}$ \\
\hline & Post-surgical dysfunction $(\mathrm{n}=51)$ & $\begin{array}{l}\text { Post-heart surgery } \\
\text { Dysfunction subsequent to heart transplant }\end{array}$ \\
\hline \multirow{2}{*}{$\begin{array}{l}\text { Pulmonary Thromboembolism } \\
(\mathrm{n}=29)\end{array}$} & Acute PTE $(n=18)$ & \\
\hline & $\begin{array}{l}\text { Chronic thromboembolic disease } \\
(\mathrm{n}=11)\end{array}$ & \\
\hline Pneumopathy $(\mathrm{n}=18)$ & Chronic pneumopathy $(\mathrm{n}=18)$ & \\
\hline \multirow{2}{*}{$\begin{array}{l}\text { Idiopathic Pulmonary Arterial } \\
\text { Hypertension/Immune Cause } \\
(\mathbf{n}=8)\end{array}$} & Autoimmune diseases $(\mathrm{n}=2)$ & \\
\hline & Idiopathic PAH $(\mathrm{n}=6)$ & \\
\hline
\end{tabular}

valvulopathy (moderate or severe degree) and congenital cardiopathy.

Right ventricular dysfunction secondary to pulmonary thromboembolism was encoded in a different category following international criteria $[\mathbf{2 7}, \mathbf{2 8}]$ distinguishing between acute and chronic embolism.

Whatever etiology of chronic pneumopathy (pulmonary obstructive disease, restrictive disease, apnea hypopnea syndrome...) different to immune or idiopathic pulmonary arterial hypertension was included in the pneumopathy category.

The general group and the etiological category, as well as the specific disease responsible for RVD, were defined for all patients included. In addition, their general clinical data, such as gender and age, were also collected.

\section{Statistical methods}

The prevalence of right ventricular dysfunction was calculated from all the echocardiographs selected, taking into consideration the number of patients who met the indicated echocardiographic criterion. Continuous parameters were expressed as mean and standard deviation (SD) and qualitative parameters as absolute figures and percentages.

A comparison of continuous and qualitative variables was performed using Student's t-test, Anova and $x^{2}$.

Comparisons that reached $p<0.05$ were considered to be statistically significant. The statistics program used was SPSS v.15 for Windows.

\section{Results}

Prevalence and causes for right ventricular dysfunction During the twenty months that the recruiting period lasted, a total of 7636 transthoracic echocardiograms, in which right ventricular function was assessed, were included. 442 cases met the condition for right ventricular dysfunction, which is $5.78 \% .87 .56 \%$ of the patients included presented a cardiac cause as the reason for RVD. The remaining $12.44 \%$ of the patients had a non-cardiac cause for RVD (pulmonary thromboembolism: 6.56\%; pneumopathy: 4.07\%; autoimmune/ idiopathic pulmonary arterial hypertension: $1.81 \%)$.

In the cardiac etiological category, the most common group was that of chronic cardiopathy, with 250 patients (64.59\% within this category). The etiological distribution within this group showed 3 main types of involvement: valvular (44\%), idiopathic dilated cardiomyopathy (23\%) and ischemic cardiomyopathy $(21 \%)$. The remaining patients were distributed among less common diagnoses (hypertensive cardiomyopathy, hypertrophic cardiomyopathy, tachycardiomyopathy, and other).

Acute heart failure as the cause for RVD was reduced to 12 patients (3.1\% of the cardiac category) and in all cases they were acute myocardial infarction with right ventricular involvement.

The second most frequent group among those with RVD of cardiac origin was congenital heart disease (74 cases, $19.12 \%$ of those with cardiac cause). The most frequent pathophysiological model was right ventricular volume overload (45\%), mainly due to patients with pulmonary valve regurgitation as a consequence of prior surgical interventions. The second most frequent model among congenital heart diseases was systemic right ventricle (24\%), which included patients with congenitally corrected transposition of the great vessels and patients with transposition of great vessels corrected using Senning and Mustard techniques. Still in the group of congenital heart disease causing RVD, 22\% of patients presented a significant RV pressure overload (valvular, subvalvular or pulmonary supravalvular stenosis), and $9 \%$ of these cases developed RVD as a consequence of pulmonary arterial hypertension due to a longstanding systemic-pulmonary shunt.

The third group within those with RVD of cardiac origin comprised RVD patients within the context of heart surgery. 
Buendia-Fuentes et al. Cardiovascular System 2014,

http://www.hoajonline.com/journals/pdf/2052-4358-2-1.pdf

doi: $10.7243 / 2052-4358-2-1$

Table 2. Differences in age, sex and echocardiographic characteristics among the various etiological categories.

\begin{tabular}{lllllc}
\hline & $\begin{array}{l}\text { Cardiac } \\
\mathbf{n = 3 8 7}\end{array}$ & $\begin{array}{l}\text { PTE } \\
\mathbf{n = 2 9}\end{array}$ & $\begin{array}{l}\text { IPAH+Autoimmune } \\
\mathbf{n = 8}\end{array}$ & $\begin{array}{l}\text { Pneumopathy } \\
\mathbf{n = 1 8}\end{array}$ & \multicolumn{1}{c}{$\mathbf{p}$} \\
\hline Age (years) & $56.61 \pm 19.54$ & $70.63 \pm 12.02$ & $60.75 \pm 8.46$ & $62.89 \pm 16.29$ & 0.002 \\
Men (\%) & 64.59 & 41.38 & 12.5 & 33.33 & $<0.001$ \\
LVEF (\%) & $29.05 \pm 16.96$ & $57.33 \pm 36.25$ & $62.19 \pm 28.28$ & $58.32 \pm 19.26$ & 0.002 \\
LVTDD (mm) & $53.68 \pm 13.48$ & $35.88 \pm 19.15$ & $45.25 \pm 5.96$ & $42.7 \pm 6.39$ & $<0.001$ \\
LVTSD (mm) & $41.91 \pm 15.34$ & $22.38 \pm 14.45$ & $28.75 \pm 6.18$ & $27 \pm 7.41$ & $<0.001$ \\
TAPSE(mm) & $12.83 \pm 3.32$ & $10.54 \pm 6.75$ & $15.02 \pm 4.58$ & $14.22 \pm 3.73$ & 0.67 \\
RV DIAM (mm) & $45.64 \pm 8.65$ & $35.83 \pm 11.05$ & $51.33 \pm 8.08$ & $44.4 \pm 4.16$ & $<0.001$ \\
S' $^{\prime}(\mathrm{cm} / \mathrm{s})$ & $7.87 \pm 2.06$ & $5.72 \pm 4.53$ & $9.33 \pm 1.15$ & $10.43 \pm 2.96$ & 0.002 \\
TI & $2.11 \pm 1.27$ & $0.93 \pm 0.62$ & $3.25 \pm 1.5$ & $1.38 \pm 0.74$ & 0.001 \\
sPAP(mmHg) & $54.65 \pm 19.43$ & $57.50 \pm 23.14$ & $80.50 \pm 10.27$ & $68.33 \pm 18.29$ & 0.001 \\
\hline
\end{tabular}

LVEF: left ventricular ejection fraction, LVTDD: left ventricle telediastolic diameter, LVTSD: left ventricle telesystolic diameter, RV DIAM: right ventricle basal diameter, TI: tricuspid insufficiency, sPAP: systolic pulmonary artery pressure

Basically, these were patients with valve replacement or repair operations $(49 \%)$ or patients in post-surgical heart transplant (31\%).

\section{General characteristics of the different etiological cat-} egories

The comparison of echocardiographic data, age and sex among the different etiological categories provided data regarding the characteristic profile of patients in each category, as shown in (Table 2).

The mean age of patients included in the study was 57.83 SD 19.18 years. There was a statistically significant difference in the distribution of this variable among the four categories $(p=0.002)$. The pulmonary thromboembolism category had the oldest mean age (70.63 SD 12.02 years), and RVD of cardiac origin offered the youngest mean age (56.61 SD 19.54).

Of the 442 patients included, $60.9 \%$ were men. Among those who had RVD of cardiac origin, this percentage was $64.59 \%$, which was much higher than the percentage of men in other groups (PTE: $41.38 \%$, Autoimmune and IPAH: $12.5 \%$, Pneumopathy: 33.33\%).

In terms of right ventricle echocardiographic data, patients with RVD of non-cardiac origin had left ventricular function and diameters within normal limits. However, patients classified as having RVD of cardiac origin showed a significant worsening of left ventricular function (LVEF: 29.05 SD 16.96\%) with telesystolic and telediastolic diameters in the upper limits of normality (53.68 SD $13.48 \mathrm{~mm}$ and 41.91 SD 15.34 $\mathrm{mm}$, respectively).

Globally, data on right ventricular dysfunction in patients were summarized as TAPSE=12.77 SD $3.73 \mathrm{~mm}, \mathrm{~S}^{\prime}=7.87 \mathrm{SD} 2.45$ $\mathrm{cm} / \mathrm{s}$ and right ventricular dilation with a basal RV diameter of 44.05 SD $11.54 \mathrm{~mm}$. There were no differences in TAPSE among the four categories, but there were differences in
$S^{\prime}$, with greater involvement of patients who had suffered a RVD caused by PTE.

Patients with RVD due to autoimmune or idiopathic pulmonary arterial hypertension demonstrated a systolic pulmonary artery pressure greater than those in the other three categories, as well as greater right ventricular dilation and a greater tricuspid regurgitation. Systolic pulmonary artery pressure was higher than $50 \mathrm{mmHg}$ on average in the four categories.

\section{General characteristics within the category of RVD of cardiac origin}

The most frequent etiological category (RVD of cardiac origin) was divided, in turn, into four general types of cardiac involvement according to their pathophysiological origin (systolic dysfunction, diastolic dysfunction, valvulopathy and congenital cardiopathy). The patients comprising each of these groups showed different characteristics in terms of age, sex, and the function and size of the right ventricle. Specific details are summarized in (Table 3 ).

As can be expected, the congenital heart disease group was younger than the others ( 32.85 SD 15.97 years); the mean age in the rest of the groups was 62.42 SD 15.55 years.

Gender distribution was quite balanced in the diastolic dysfunction, valvulopathy and congenital cardiopathy groups. However, the systolic dysfunction group showed a predominance of the male gender at $81.53 \%$ men.

In terms of systolic function, this was deteriorated in the group with systolic dysfunction (LVEF=25.02 SD 9.89\%) and in the group with valvulopathy (30.41 SD 18.32\%), but was normal with a slight deterioration in the other two groups. The degree of right ventricular dilation and dysfunction estimated using TAPSE, $S^{\prime}$ and right ventricular basal diameter showed no differences among the four groups. 
Buendia-Fuentes et al. Cardiovascular System 2014,

http://www.hoajonline.com/journals/pdf/2052-4358-2-1.pdf

Table 3. Age, sex and echocardiographic characteristics of RVD patients of cardiac origin, comparing among four proposed physiopathological models.

\begin{tabular}{llllll}
\hline & $\begin{array}{l}\text { Systolic } \\
\mathbf{n = 1 5 7}\end{array}$ & $\begin{array}{l}\text { Diastolic } \\
\mathbf{n = 1 8}\end{array}$ & $\begin{array}{l}\text { Valvular } \\
\mathbf{n = 1 3 8}\end{array}$ & $\begin{array}{l}\text { Congenital } \\
\mathbf{n = 7 4}\end{array}$ & $\mathbf{p}$ \\
\hline Age (years) & $59.27 \pm 16.1$ & $65.88 \pm 19.66$ & $65.46 \pm 13.54$ & $32.85 \pm 15.97$ & $<0.001$ \\
Men (\%) & 81.53 & 50 & 51.45 & 56.76 & $<0.001$ \\
LVEF (\%) & $25.02 \pm 9.89$ & $55.88 \pm 34.85$ & $30.41 \pm 18.32$ & $45.75 \pm 16.39$ & $<0.001$ \\
LVTDD (mm) & $58.54 \pm 12.94$ & $52.3 \pm 11.55$ & $52.28 \pm 13.82$ & $44.04 \pm 7.74$ & $<0.001$ \\
LVTSD (mm) & $49.1 \pm 14.75$ & $38.56 \pm 15.53$ & $38.89 \pm 13.66$ & $27.95 \pm 5.77$ & $<0.001$ \\
LVTDD (mm) & $11.93 \pm 3.3$ & $13.4 \pm 1.14$ & $13.07 \pm 30.6$ & $13.74 \pm 3.62$ & 0.54 \\
RV DIAM (mm) & $43.86 \pm 11.45$ & $42.03 \pm 6.88$ & $45.24 \pm 5.58$ & $48.68 \pm 8.20$ & 0.247 \\
S' (cm/s) & $7.6 \pm 2.46$ & $9.25 \pm 0.35$ & $8.06 \pm 1.89$ & $7.86 \pm 1.85$ & 0.613 \\
TI & $1.8 \pm 1.11$ & $1.75 \pm 0.71$ & $2.55 \pm 1.37$ & $2.14 \pm 1.39$ & 0.012 \\
sPAP(mmHg) & $48.91 \pm 15.65$ & $60.92 \pm 17.71$ & $59.67 \pm 18.92$ & $57.11 \pm 30.42$ & 0.001 \\
\hline
\end{tabular}

LVEF: left ventricular ejection fraction, LVTDD: left ventricle telediastolic diameter, LVTSD: left ventricle telesystolic diameter, RV DIAM: right ventricle basal diameter, TI: tricuspid insufficiency, sPAP: systolic pulmonary artery pressure

Systolic pressure in the pulmonary artery was greater in the group with diastolic dysfunction and valvulopathy (60.92 SD $17.71 \mathrm{mmHg}$ and 59.67 SD $18.92 \mathrm{mmHg}$, respectively) with significantly lower figures in the group with systolic dysfunction (48.91 SD $15.65 \mathrm{mmHg}$ ).

\section{Characteristics of the different groups based on whether or not PHT is present}

Of the 442 cases included in the study, sPAP could be estimated in 245 cases, which is $55.4 \%$ of the total. Among the patients in which this hemodynamic parameter could be estimated, 121 presented pulmonary hypertension (sPAP>50 $\mathrm{mmHg}$ ).

Within the group of RVD of cardiac origin, $58.74 \%$ presented a sPAP> $50 \mathrm{mmHg}$. However, in the other three categories, $86.11 \%$ of the patients presented pulmonary hypertension (Figure 2).

As represented in (Figure 3 ), patients with a sPAP $>50$ $\mathrm{mmHg}$ showed a greater degree of right and left ventricular dilation, as well as a greater degree of tricuspid regurgitation. Although not statistically significant $(p=0.078)$, PHT patients were slightly older than non-PHT patients (63.02 SD 17.73 years and 58.64 SD 16.95 years, respectively). No differences were observed with regard to distribution by sex $(53.72 \%$ were men in the PHT group and $40.32 \%$ were men in the non-PHT group; $p=0.081$ ).

Centering the analysis on the 250 patients with RVD of a chronic cardiac cause, the sPAP could be estimated in 206 cases (82.4\%). When we compare the existence of PHT in the four types of cardiac involvement according to their pathophysiological origin, PHT is much more common in patients with valvulopathies (71.95\%) and with diastolic dysfunction (66.66\%); but less frequent in the other two types (systolic dysfunction: $48.38 \%$ and congenital cardiopathy: $43.37 \%)$. These differences were significant $(p=0.01)$.
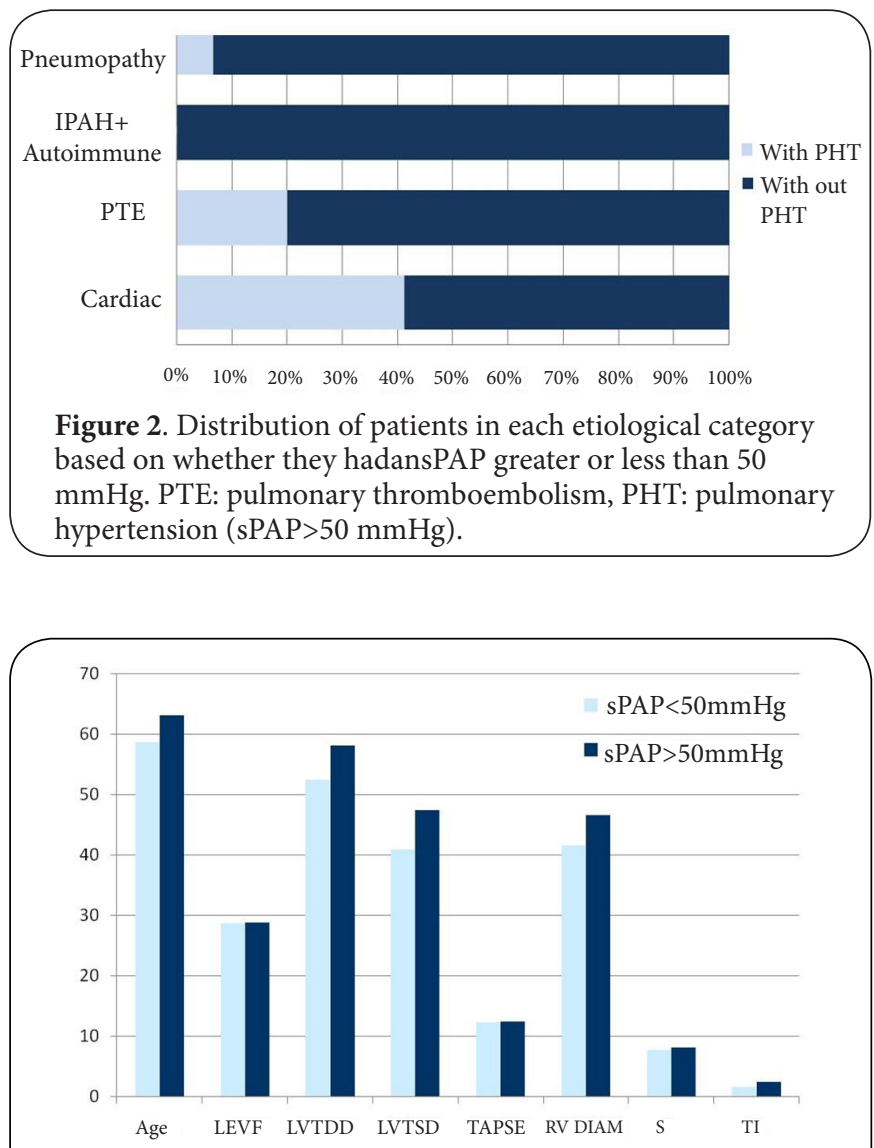

Figure 3. Comparison of ages and echocardiographic parameters between patients with and without pulmonary hypertension $(\mathrm{sPAP}>50 \mathrm{mmHg}){ }^{*}=\mathrm{p}<0.05$. (LVEF: left ventricular ejection fraction, LVTDD: left ventricle telediastolic diameter, LVTSD: left ventricle telesystolic diameter, RV DIAM: right ventricle basal diameter, TI: tricuspid insufficiency, sPAP: systolic pulmonary artery pressure. 
Buendia-Fuentes et al. Cardiovascular System 2014,

http://www.hoajonline.com/journals/pdf/2052-4358-2-1.pdf

doi: 10.7243/2052-4358-2-1

Table 4. Comparison of each physiopathological type of RVD by cardiopathy, according to the presence or absence of pulmonary hypertension (sPAP> $50 \mathrm{mmHg}$ ).

\begin{tabular}{|c|c|c|c|c|c|c|c|c|c|c|c|c|}
\hline & \multicolumn{3}{|c|}{ Systolic } & \multicolumn{3}{|c|}{ Diastolic } & \multicolumn{3}{|c|}{ Valvular } & \multicolumn{3}{|c|}{ Congenital } \\
\hline & $\begin{array}{l}\mathrm{sPAP}>50 \\
\mathrm{n}=45\end{array}$ & $\begin{array}{l}\mathrm{sPAP}<50 \\
\mathrm{n}=48\end{array}$ & $\mathbf{p}$ & $\begin{array}{l}\mathrm{sPAP}>50 \\
\mathrm{n}=8\end{array}$ & $\begin{array}{l}\mathrm{sPAP}<50 \\
\mathrm{n}=4\end{array}$ & $\mathbf{p}$ & $\begin{array}{l}\mathrm{sPAP}>50 \\
\mathrm{n}=59\end{array}$ & $\begin{array}{l}\text { sPAP }<50 \\
n=23\end{array}$ & $\mathbf{p}$ & $\begin{array}{l}\mathrm{sPAP}>50 \\
\mathrm{n}=9\end{array}$ & $\begin{array}{l}\mathrm{sPAP}<50 \\
\mathrm{n}=10\end{array}$ & $\mathbf{p}$ \\
\hline Age (years) & $59.9 \pm 15.5$ & $60.6 \pm 13.6$ & 0.820 & $61.9 \pm 23.1$ & $80.2 \pm 3.3$ & 0.152 & $70.2 \pm 11.4$ & $60.4 \pm 16.4$ & 0.016 & $33.7 \pm 23.8$ & $37.3 \pm 15.8$ & 0.698 \\
\hline LVEF (\%) & $21.2 \pm 8.6$ & $26.6 \pm 9.5$ & 0.024 & $52.2 \pm 18.4$ & $54.5 \pm 19.1$ & 0.275 & $31.3 \pm 18.6$ & $40.2 \pm 21.8$ & 0.397 & $51.3 \pm 15.3$ & $56.2 \pm 16.9$ & 0.257 \\
\hline LVTDD (mm) & $65.1 \pm 12.4$ & $54.9 \pm 9.8$ & $<0.001$ & $52.3 \pm 5.1$ & $43 \pm 10.6$ & 0.240 & $54.3 \pm 10.6$ & $52.3 \pm 8.6$ & 0.462 & $40.4 \pm 7.5$ & $41 \pm 6.5$ & 0.89 \\
\hline LVTSD (mm) & $56.8 \pm 14.4$ & $45.9 \pm 11.5$ & $<0.001$ & $34.2 \pm 4.5$ & $27.5 \pm 3.5$ & 0.123 & $41.1 \pm 12.4$ & $37.6 \pm 11$ & 0.299 & $26.3 \pm 6.6$ & $23.8 \pm 4.2$ & 0.505 \\
\hline TAPSE (mm) & $11.3 \pm 2.8$ & $11.3 \pm 3.8$ & 0.986 & $13.3 \pm 1.5$ & $13.5 \pm 0.7$ & 0.898 & $13.1 \pm 3.2$ & $12.4 \pm 1.6$ & 0.482 & $13 \pm 2.91$ & $14 \pm 3.9$ & 0.641 \\
\hline RV DIAM (mm) & $47 \pm 8.1$ & $37.9 \pm 10.3$ & 0.084 & $42.9 \pm 5.9$ & $45.3 \pm 9.8$ & 0.225 & $45.5 \pm 5.6$ & $44.1 \pm 3.3$ & 0.478 & $45.2 \pm 8.9$ & $43.5 \pm 6.6$ & 0.125 \\
\hline $\mathrm{S}^{\prime}(\mathrm{cm} / \mathrm{s})$ & $7.8 \pm 1.2$ & $7.4 \pm 3.7$ & 0.747 & $9.25 \pm 2.5$ & $9.56 \pm 3.1$ & 0.586 & $8.4 \pm 1.9$ & $7.6 \pm 1.3$ & 0.297 & $7.5 \pm 1.8$ & $8.3 \pm 1.2$ & 0.429 \\
\hline $\mathrm{TI}$ & $2.3 \pm 1.2$ & $1.6 \pm 0.8$ & 0.012 & $1.6 \pm 0.5$ & $2 \pm 1$ & 0.482 & $2.7 \pm 1.3$ & $2.2 \pm 1.4$ & 0.239 & $2.5 \pm 1.7$ & $0.8 \pm 0.4$ & 0.069 \\
\hline $\operatorname{sPAP}(\mathrm{mmHg})$ & $61.5 \pm 10.2$ & $37.1 \pm 9.4$ & $<0.001$ & $69.5 \pm 15.4$ & $43.7 \pm 2.5$ & 0.002 & $68 . \pm 14.3$ & $38.2 \pm 10.6$ & $<0.001$ & $82.8 \pm 25$ & $34 \pm 6.6$ & $<0.001$ \\
\hline
\end{tabular}

(LVEF: left ventricular ejection fraction, LVTDD: left ventricle telediastolic diameter, LVTSD: left ventricle telesystolic diameter, RV DIAM: right ventricle basal diameter, TI: tricuspid insufficiency, sPAP: systolic pulmonary artery pressure).

Table 4 summarizes the distribution of age and echocardiographic characteristics in these groups according to the existence of PHT.

\section{Discussion}

In recent years, following the recommendations of the National Heart, Lung and Blood Institute (2006), various groups have focused on the study of the right ventricle [2,6-11]. Along these lines, the present work shows a cross-sectional and global vision of right ventricular dysfunction at a specialized hospital center.

The importance of RVD has gone unnoticed for a long time [29]. However, recent studies have proved that RVD is an independent factor for mortality in various groups of patients, with both cardiac and extracardiac (sepsis, pulmonary thromboembolism, pulmonary arterial hypertension) pathologies $[12-14,16-22,30]$. These conclusions were obtained from studies focused on specific etiological categories that may be associated with a deterioration of the right ventricular function. However, there are no major epidemiological studies on the general healthy population or diseased population focusing on RVD. The specialized hospital environment provides an interesting model for the study of the prevalence of RVD in a specific diseased population, as well as the causes behind this dysfunction.

Using descriptive and epidemiological approach, the present study aims at obtaining previously-unpublished data about RVD at a specialized hospital with the objective of specifying the magnitude of the problem and establishing the basis for the potential formation of multidisciplinary groups specialized in dealing with this pathology.

A prevalence of right ventricular dysfunction of $5.78 \%$ among all the echocardiographic studies performed at the hospital means that there is a large enough volume to reaffirm the importance of RVD in the hospital environment.

With respect to RVD of cardiac origin, the most frequent cause is chronic cardiopathy. In turn, within this group, ischemic, valvular and idiopathic dilated cardiomyopathy etiologies account for the vast majority of cases (88\%). It should be noted that only $7.2 \%$ of the patients with RVD of chronic cardiac origin are classified in the pathophysiological type of diastolic dysfunction, although given the patients' age and the high prevalence of AHT in the general population, a greater frequency of these types of patients should be expected. The specialized hospital environment can offer an explanation for these data, since the present study does not include the outpatient follow-up of stable patients, rather it focuses on medical examinations of patients with heart disease in advanced stages or in patients admitted to hospital due to clinical instability. The characteristics of the hospital also explain the considerable number of patients with RVD due to congenital cardiopathy (74 patients) or following cardiac surgery (51 patients), which would be very difficult to explain in another health care context.

The large number of patients with RVD of cardiac origin has allowed for a specific analysis of this category, dividing it into four pathophysiological models (systolic dysfunction, diastolic dysfunction, valvulopathy and congenital cardiopathy). From this analysis, the involvement of left ventricular systolic function is notable in the group with systolic dysfunction and valvular involvement, whereas these remain normal in the other two groups (diastolic dysfunction and congenital cardiopathy). Furthermore, the high sPAP presented by all groups should be noted, especially in those with diastolic dysfunction 
(60.92 SD $17.71 \mathrm{mmHg}$ ). The group with systolic dysfunction was the only one with an average sPAPunder $50 \mathrm{mmHg}$. Analyses of the data based on the existence of pulmonary arterial hypertension show that those with extracardiac causes of RVD more frequently have ansPAP> $50 \mathrm{mmHg}(86.11 \%)$ than those with RVD of cardiac origin (58.74\%). It is logical to think that in a heart free from intrinsic lesions, the most common way to end up in a state of right ventricular dysfunction is to develop PHT. However, apart from PHT, there are other ways for patients with intrinsic heart disease to reach a certain degree of RVD (ischemic cardiopathy, RV pressure or volume overload due to valvulopathies, myocarditis...).

The global characteristics of patients with an SPAP $>50$ $\mathrm{mmHg}$ have greater ventricular dilation, both left and right, which leads us to believe that these are pathological processes with greater progression and; therefore, greater structural involvement.

The fact that echocardiographic criteria were selected to define RVD lends a certain degree of error in the diagnosis, due to the presence of both false-positives and false-negatives. The characteristics of the study made the selection of echocardiography advisable, given its widespread availability and its low cost.

There was a bias in the selection of patients because it was performed in a specific health care environment (reference hospital). Therefore, the data obtained in this study should not be extended to other clinical contexts in which patients or healthy populations are included in a different clinical environment. However, to date, there is no other consecutive, single-center, epidemiological study with such a high number of patients that comprises all of the etiological causes that could affect right ventricular function, including conventional heart surgery and transplants. Therefore, we believe that this record has a very high clinical impact, and clarifies existing pathologies at a reference hospital with respect to right ventricular dysfunction.

\section{Conclusion}

Despite recent efforts in the study of the right ventricle, there are certain gaps both in knowledge of its pathophysiology and in the significance the dysfunction has in daily clinical practice. The present epidemiological study on right ventricular dysfunction presents, for the first time, data on the prevalence and etiological distribution of RVD at a specialized hospital. With a prevalence of $5.78 \%$, the importance of this pathology within the hospital environment is confirmed. Among the etiological factors responsible, RVD of cardiac origin the front runner with more than $85 \%$ of cases. The remaining patients presented other extracardiac pathologies, thus indicating the forming of multidisciplinary groups for the study and monitoring of this pathology.

\section{Competing interests}

The authors declare that they have no competing interests.

\section{Authors' contributions}

\begin{tabular}{|l|c|c|c|c|c|c|c|c|c|c|}
\hline $\begin{array}{l}\text { Authors' } \\
\text { contributions }\end{array}$ & FBF & LAB & RVG & JBM & RL & AOS & LMD & ISL & VMP & ASS \\
\hline $\begin{array}{l}\text { Research } \\
\text { concept and } \\
\text { design }\end{array}$ & $\checkmark$ & $\checkmark$ & -- & -- & -- & -- & $\checkmark$ & $\checkmark$ & - & - \\
\hline $\begin{array}{l}\text { Collection and/or } \\
\text { assembly of data }\end{array}$ & $\checkmark$ & -- & $\checkmark$ & $\checkmark$ & $\checkmark$ & $\checkmark$ & -- & -- & $\checkmark$ & - \\
\hline $\begin{array}{l}\text { Data analysis and } \\
\text { interpretation }\end{array}$ & $\checkmark$ & $\checkmark$ & -- & -- & -- & -- & $\checkmark$ & $\checkmark$ & -- & $\checkmark$ \\
\hline Writing the article & $\checkmark$ & $\checkmark$ & -- & -- & -- & -- & $\checkmark$ & -- & - & - \\
\hline $\begin{array}{l}\text { Critical revision of } \\
\text { the article }\end{array}$ & $\checkmark$ & $\checkmark$ & $\checkmark$ & $\checkmark$ & $\checkmark$ & $\checkmark$ & $\checkmark$ & $\checkmark$ & $\checkmark$ & $\checkmark$ \\
\hline $\begin{array}{l}\text { Final approval of } \\
\text { article }\end{array}$ & -- & -- & -- & -- & -- & -- & $\checkmark$ & -- & -- & $\checkmark$ \\
\hline Statistical analysis & $\checkmark$ & -- & -- & -- & -- & $\checkmark$ & -- & -- & -- & - \\
\hline
\end{tabular}

Acknowledgement

To Pfizer for the translation of texts and their support for the DIFUNDE Study Group's projects.

Publication history

EIC: William Clifford Roberts, Baylor University Medical Center, USA. Received: 12-Dec-2013 Revised: 22-Dec-2013

Accepted: 08-Jan-2014 Published: 25-Jan-2014

\section{References}

1. Torrent-Guasp F. Structure and function of the heart. Rev Esp Cardiol. 1998; 51:91-102. I Article I PubMed

2. Zarco P. The right ventricle revisited. Rev Esp Cardiol. 2001; 54:938-40. | PubMed

3. Lee FA. Hemodynamics of the right ventricle in normal and disease states. Cardiol Clin. 1992; 10:59-67. I PubMed

4. Magder S. The left heart can only be as good as the right heart: determinants of function and dysfunction of the right ventricle. Crit Care Resusc. 2007; 9:344-51. I Pdf I PubMed

5. Rigolin VH, Robiolio PA, Wilson JS, Harrison JK and Bashore TM. The forgotten chamber: the importance of the right ventricle. Cathet Cardiovasc Diagn. 1995; 35:18-28. | Article | PubMed

6. Greyson CR. Pathophysiology of right ventricular failure. Crit Care Med. 2008; 36:S57-65. | Article | PubMed

7. Greyson $\mathrm{CR}$. The right ventricle and pulmonary circulation: basic concepts. Rev Esp Cardiol. 2010; 63:81-95. I Article I PubMed

8. Haddad F, Doyle R, Murphy DJ and Hunt SA. Right ventricular function in cardiovascular disease, part II: pathophysiology, clinical importance, and management of right ventricular failure. Circulation. 2008; 117:1717-31. | Article | PubMed

9. Haddad F, Hunt SA, Rosenthal DN and Murphy DJ. Right ventricular function in cardiovascular disease, part I: Anatomy, physiology, aging, and functional assessment of the right ventricle. Circulation. 2008; 117:1436-48. | Article | PubMed

10. Ho SY and Nihoyannopoulos P. Anatomy, echocardiography, and normal right ventricular dimensions. Heart. 2006; 92:i2-13. | Article | PubMed Abstract | PubMed Full Text

11. Markel TA, Wairiuko GM, Lahm T, Crisostomo PR, Wang M, Herring $\mathrm{CM}$ and Meldrum DR. The right heart and its distinct mechanisms of development, function, and failure. J Surg Res. 2008; 146:304-13. I Article I PubMed

12. de Groote P, Millaire A, Foucher-Hossein C, Nugue O, Marchandise X, Ducloux $G$ and Lablanche JM. Right ventricular ejection fraction is an independent predictor of survival in patients with moderate heart failure. J Am Coll Cardiol. 1998; 32:948-54. I Article I PubMed 
Buendia-Fuentes et al. Cardiovascular System 2014,

http://www.hoajonline.com/journals/pdf/2052-4358-2-1.pdf

doi: $10.7243 / 2052-4358-2-1$

13. Di Salvo TG, Mathier M, Semigran MJ and Dec GW. Preserved right ventricular ejection fraction predicts exercise capacity and survival in advanced heart failure. J Am Coll Cardiol. 1995; 25:1143-53. I Article | PubMed

14. Gavazzi A, Berzuini C, Campana C, Inserra C, Ponzetta M, Sebastiani R, Ghio $S$ and Recusani F. Value of right ventricular ejection fraction in predicting short-term prognosis of patients with severe chronic heart failure. J Heart Lung Transplant. 1997; 16:774-85. | PubMed

15. Ghio $S$ and Tavazzi L. Right ventricular dysfunction in advanced heart failure. Ital Heart J. 2005; 6:852-5. | Pdf | PubMed

16. Mehta SR, Eikelboom JW, Natarajan MK, Diaz R, Yi C, Gibbons RJ and Yusuf S. Impact of right ventricular involvement on mortality and morbidity in patients with inferior myocardial infarction. J Am Coll Cardiol. 2001; 37:37-43. | Article | PubMed

17. Polak JF, Holman BL, Wynne J and Colucci WS. Right ventricular ejection fraction: an indicator of increased mortality in patients with congestive heart failure associated with coronary artery disease. J Am Coll Cardiol. 1983; 2:217-24. | Article | PubMed

18. Davlouros PA, Niwa K, Webb G and Gatzoulis MA. The right ventricle in congenital heart disease. Heart. 2006; 92 Suppl 1:i27-38. | Article | PubMed Abstract | PubMed Full Text

19. Warnes CA. Transposition of the great arteries. Circulation. 2006; 114:2699-709. | Article | PubMed

20. Hirsh J and Hoak J. Management of deep vein thrombosis and pulmonary embolism. A statement for healthcare professionals. Council on Thrombosis (in consultation with the Council on Cardiovascular Radiology), American Heart Association. Circulation. 1996; 93:2212-45. | Article | PubMed

21. Maeder M, Fehr T, Rickli H and Ammann P. Sepsis-associated myocardial dysfunction: diagnostic and prognostic impact of cardiac troponins and natriuretic peptides. Chest. 2006; 129:1349-66. | Article I PubMed

22. Vieillard-Baron A and Jardin F. Why protect the right ventricle in patients with acute respiratory distress syndrome? Curr Opin Crit Care. 2003; 9:15-21. | Article | PubMed

23. Juilliere Y, Barbier G, Feldmann L, Grentzinger A, Danchin N and Cherrier F. Additional predictive value of both left and right ventricular ejection fractions on long-term survival in idiopathic dilated cardiomyopathy. Eur Heart J. 1997; 18:276-80. | Article | PubMed

24. O'Rourke RA and Dell'Italia LJ. Diagnosis and management of right ventricular myocardial infarction. Curr Probl Cardiol. 2004; 29:6-47. | Article | PubMed

25. Hammarstrom E, Wranne B, Pinto FJ, Puryear J and Popp RL. Tricuspid annular motion. J Am Soc Echocardiogr. 1991; 4:131-9. | PubMed

26. Meluzin J, Spinarova L, Bakala J, Toman J, Krejci J, Hude P, Kara T and Soucek M. Pulsed Doppler tissue imaging of the velocity of tricuspid annular systolic motion; a new, rapid, and non-invasive method of evaluating right ventricular systolic function. Eur Heart J. 2001; 22:3408. | Article | PubMed

27. Hoeper MM, Mayer E, Simonneau G and Rubin LJ. Chronic thromboembolic pulmonary hypertension. Circulation. 2006; 113:201120. | Article | PubMed

28. Torbicki A, Perrier A, Konstantinides S, Agnelli G, Galie N, Pruszczyk P, Bengel F, Brady AJ, Ferreira D, Janssens U, Klepetko W, Mayer E, RemyJardin $M$ and Bassand JP. Guidelines on the diagnosis and management of acute pulmonary embolism: the Task Force for the Diagnosis and Management of Acute Pulmonary Embolism of the European Society of Cardiology (ESC). Eur Heart J. 2008; 29:2276-315. I Article I PubMed

29. Segovia J, Bermejo J, Alfonso F and Heras M. The right heart and pulmonary circulation: is it really a minor circulation? Rev Esp Cardiol. 2010; 63:77-80. | Article | PubMed

30. Ghio S, Gavazzi A, Campana C, Inserra C, Klersy C, Sebastiani R, Arbustini $E$, Recusani F and Tavazzi L. Independent and additive prognostic value of right ventricular systolic function and pulmonary artery pressure in patients with chronic heart failure. J Am Coll Cardiol. 2001; 37:183-8. I Article I PubMed
Citation:

Buendía-Fuentes F, Almenar-Bonet L, Vicente-Guillén R, Bonastre-Mora J, López R, Osa-Sáez A, MartínezDolz L, Sánchez-Lázaro I, Miró-Palau V and SalvadorSanz A. Consecutive epidemiological study of right ventricular dysfunction at a reference hospital. Cardio Vasc Syst. 2014; 2:1.

http://dx.doi.org/10.7243/2052-4358-2-1 